\title{
Pharmacokinetics of Human Recombinant Anti-Botulinum Toxin Antibodies in Rats
}

\author{
Yero Espinoza ${ }^{1}$, David Wong ${ }^{1}$, Ago Ahene ${ }^{2}$, Kenneth Der ${ }^{3}$, Zachary Martinez ${ }^{1}$, John Pham ${ }^{4}$, \\ Ronald R. Cobb ${ }^{5}\left(\mathbb{D}\right.$, Shauna Farr-Jones ${ }^{6}{ }^{(D}$, James. D. Marks ${ }^{6}$ and Milan T. Tomic ${ }^{1, *}$ \\ 1 Ology Bioservices Inc., 630 Bancroft Way, Suite D, Berkeley, CA 94710, USA; \\ yero.espinoza@ologybio.com (Y.E.); david.wong@ologybio.com (D.W.); zach.martinez@ologybio.com (Z.M.) \\ 2 Fiveprime Therapeutics Inc., 111 Oyster Point Blvd, South San Francisco, CA 94080, USA; \\ ago.ahene@fiveprime.com \\ 3 Portola Pharmaceuticals Inc., 270 E Grand Ave, South San Francisco, CA 94080, USA; kder@portola.com \\ 4 OncoMed Inc., 800 Chesapeake Dr, Redwood City, CA 94063, USA; Jtpham2015@yahoo.com \\ 5 Ology Bioservices Inc., 13200 NW Nano Ct, Alachua, FL 32615, USA; ron.cobb@ologybio.com \\ 6 Department of Anesthesia and Perioperative Care, University of California, San Francisco, 1001 Potrero Ave, \\ San Francisco, CA 94110, USA; shauna.farr-jones@ucsf.edu (S.F.-J.); jim.marks@ucsf.edu (J.D.M.) \\ * Correspondence: milan.tomic@ologybio.com; Tel.: +1-510-401-9238
}

Received: 30 April 2019; Accepted: 3 June 2019; Published: 17 June 2019

\begin{abstract}
Botulinum neurotoxins (BoNT) are potential biothreat agents due to their high lethality, potency, and ease of distribution, thus the development of antitoxins is a high priority to the US government. This study examined pre-clinical pharmacokinetic studies in rats of four oligoclonal anti-BoNT mAb-based therapeutics (NTM-1631, NTM-1632, NTM-1633, NTM-1634) for five BoNT serotypes (A, B, E, C, and D). NTM-1631, NTM-1632, and NTM-1633 each consist of three IgG1 $\mathrm{mAbs}$, each with a distinct human or humanized variable region which bind to distinct epitopes on BoNT serotype A, B, or E respectively. NTM-1634 consists of four human immunoglobulin G1 (IgG1) mAbs binding BoNT C/D mosaic toxins. The mechanism of these antitoxins requires that three antibodies simultaneously bind toxin to achieve rapid clearance. Rats (total 378) displayed no adverse clinical signs attributed to antibody treatment from any of the antitoxins. Pharmacokinetic evaluation demonstrated that the individual $\mathrm{mAbs}$ are slowly eliminated, exhibiting dose-dependent exposure and long elimination half-lives ranging from 6.5 days to 10 days. There were no consistent differences observed between males and females or among the individual antibodies in each formulation in half-life. Anti-drug antibodies (ADA) were observed, as expected for human antibodies administered to rats. The results presented were used to support the clinical investigation of antibody-based botulism antitoxins.
\end{abstract}

Keywords: botulinum neurotoxin; pharmacokinetics; recombinant antibody; rat; oligoclonal antibody; anti-botulinum neurotoxin antibody

Key Contribution: This study evaluates the pharmacokinetics of four oligoclonal antibody-based antitoxins for botulinum neurotoxin serotypes in rodents. A limitation of immune-derived antitoxins to botulinum neurotoxin is their short half-life, which can lead to re-intoxication in the case of gut colonization. This study shows that the antibodies have long half-lives and are safe in rodents. All four of these antitoxins have completed Phase 1 clinical trials.

\section{Introduction}

Botulinum toxin (BoNT) is the most potent toxin known, with a long duration of action. BoNT intoxication results in an acute, descending, symmetric flaccid paralysis caused by neurotoxin-mediated 
blockade of the presynaptic acetylcholine release. Treatment requires prolonged hospitalization [1-4]. Human botulism is caused by botulinum neurotoxin (BoNT) serotypes A, B, E, F [5-9], C, D, [10-12] and G [13].

Due to their lethality and ease of distribution, BoNTs are classified as Category A agents by the US Centers for Disease Control and Prevention (CDC) [14]. They are also Tier 1 agents as defined by the Federal Select Agent Program and are among the six agents with the highest risk for potential use as bioweapons. For example, both Iraq [15] and the former Soviet Union produced BoNT for use as weapons [16]. As a result of these threats, there is an urgent need for safe and effective therapies that could be stockpiled, as well as sensitive and rapid diagnostic tests.

The current standard of care for botulism is polyclonal antitoxin from either human or equine immunization [17-20]. Human botulism immunoglobulin, BabyBIG®, is produced by plasmapheresis of lab workers who were immunized with an investigational toxoid vaccine, and is costly [20]. Furthermore, an investigational pentavalent vaccine was recently withdrawn from clinical use due to potency concerns, and currently, no vaccine is available, thus limiting future production of BabyBIG. Equine antitoxin (BAT®) [21], comprised of immunoglobulin from serum of immunized horses, has been proteolyzed to remove the $\mathrm{Fc}_{\mathrm{C}}$ (fragment crystallizable) portion, resulting in over $90 \% \mathrm{Fab}$ (antigen binding fragment) and $\mathrm{F}\left(\mathrm{ab}^{\prime}\right)_{2}$. BAT, developed by Cangene Corp. (Winnipeg, Manitoba, Canada) has been used for botulism treatment, but it has a short half-life and can induce acute allergic responses and serum sickness, as well as induce antibodies against the equine antitoxin components [19]. BAT is also very expensive to produce-200,000 doses were manufactured under a $\$ 363$ million US government contract. For all these reasons, the US National Institute of Allergy and Infectious Diseases (NIAID) has funded discovery and development of next generation antitoxins for the treatment of botulism comprised of recombinant human monoclonal antibodies (mAbs) [17,22-25]. Recombinant human monoclonal antibodies (mAbs) would provide a renewable, and safe antitoxin that could be easily administered in mass casualty situations and sporadic cases.

Previous work found that no single anti-BoNT mAb effectively neutralizes the toxin $[17,26]$. A combination of three $\mathrm{mAbs}$ is required to effectively neutralize BoNT [17]. The oligoclonal antitoxins NTM-1631, NTM-1632, NTM-1634, NTM-1633 were developed to treat and prevent botulism due to BoNT/A, BoNT/B, BoNT/C/D and BoNT/E, respectively. NTM-1631, NTM-1632, NTM-1633 are equimolar mixtures of three IgG1 mAbs. Each mAb targets different and non-overlapping epitopes of BoNT. NTM-1634 is an equimolar mixture of four human mAbs. The antibodies bind serotypes C or D or both (unpublished).

Since the mechanism of action of these antitoxins requires the presence of all three antibodies in the mixture [17], determining the pharmacokinetics (PK) of the individual antibodies is important for determining the window of protection. The requirement for three antibodies to clear toxin means that the most rapidly cleared antibody determines protection. While the antibody mixtures are all constructed using identical framework regions, different variable region sequences were expected to affect clearance rates.

To determine the PK of each antibody, antibody-specific assays were developed. Quantitation of individual mAbs within an oligoclonal mixture targeting the same antigen presents significant technical challenges. To support pre-clinical and clinical PK studies, manufacturing and stability studies of the drug product, methods for quantitation of each mAb comprising the mixture are needed. Domain-based assays for the individual antibodies of oligoclonal mixtures of antibodies were previously developed that bind BoNT serotypes A [27], B and E [28], and C/D (unpublished). Protein domains with selected mutations were designed so that they bound only one antibody in the mixture.

Rat PK parameters for the four antitoxins reported here were used to support clinical studies with the goal of developing these drugs as a botulism treatment and post-exposure prophylaxis. 


\section{Results}

\subsection{Safety}

No adverse clinical signs attributed to treatment were observed in any dose groups after dose administration of any of the drug products. Sporadic clinical observations were observed in the groups that were administered the antibody mixtures. The clinical observations that were observed included chromodacryorrhea, exophthalmia, microphthalmia, red discharges in the noses or genitalia, alopecia, and soft stool. These effects were determined to be independent of dose by the attending veterinarian and most likely the result of the stress due to the dose administration procedures. This is because the observations occurred in 1 or 2 rats in any dose group and the observations were transient and did not persist, or they were common observations associated with restraint for blood collection.

\subsection{Pharmacokinetic Analyses NTM-1631}

Time course of NTM-1631 component mAbs in rat sera are shown in Figure 1. NTM-1631 component $\mathrm{mAb}$ are denoted XA-a, XA-b, XA-c. The PK parameters were calculated for anti-drug antibodies (ADA)-negative animals in the study (Table 1). The $\mathrm{T}_{1 / 2}$ ranged from: XA-a, 14.61 days (10 mg/kg, females) to 17.23 days $(0.1 \mathrm{mg} / \mathrm{kg}$, males); XA-b, 13.40 days $(1 \mathrm{mg} / \mathrm{kg}$, females) to 15.82 days $(0.1 \mathrm{mg} / \mathrm{kg}$, males); XA-c, 12.36 days ( $1 \mathrm{mg} / \mathrm{kg}$, females) to 16.17 days $(0.1 \mathrm{mg} / \mathrm{kg}$, males). There were no consistent differences observed in PK between males and females or amongst the three antibodies.

Table 1. Pharmacokinetic parameters of NTM-1631 for ADA-negative animals.

\begin{tabular}{|c|c|c|c|c|c|c|c|c|}
\hline Antibody & $\begin{array}{l}\text { Dose } \\
\text { mg/kg }\end{array}$ & Sex & $\mathbf{N}$ & $\mathbf{T}_{1 / 2}$ day & $\begin{array}{c}\mathrm{C}_{\max } / \text { Dose } \\
\mathrm{kg} \times \mu \mathrm{g} \\
/ \mathrm{mL} / \mathrm{mg}\end{array}$ & $\begin{array}{c}\text { AUC } \infty / \text { Dose } \\
\text { Day } \times \mathrm{kg} \times \mu \mathrm{g} \\
/ \mathrm{mL} / \mathrm{mg}\end{array}$ & $\begin{array}{c}\mathrm{CL} \\
\mathrm{mL} / \mathrm{day} / \mathrm{kg}\end{array}$ & $\begin{array}{c}\mathrm{Vc} \\
\mathrm{mL} / \mathrm{kg}\end{array}$ \\
\hline \multirow{7}{*}{ XA-a } & 0.1 & $\mathrm{M}$ & 14 & 17.23 & 8.957 & 85.6955 & 3.85 & 95.75 \\
\hline & 0.1 & $\mathrm{~F}$ & 15 & 15.56 & 11.4517 & 104.6601 & 3.15 & 70.79 \\
\hline & 1 & $\mathrm{M}$ & 7 & 16.97 & 10.00825 & 63.3717 & 4.15 & 101.62 \\
\hline & 1 & $\mathrm{~F}$ & 9 & 15.26 & 10.79059 & 97.5364 & 3.16 & 69.58 \\
\hline & 10 & $\mathrm{M}$ & 5 & 15.26 & 9.568051 & 62.5584 & 4.86 & 107.07 \\
\hline & 10 & $\mathrm{~F}$ & 10 & 14.61 & 10.454225 & 87.4375 & 3.37 & 71.04 \\
\hline & Mean & & & 15.82 & 10.18 & 83.5433 & 3.76 & 85.98 \\
\hline & SE & & & 0.43 & 0.36 & 7.09 & 0.27 & 7.09 \\
\hline \multirow{8}{*}{ XA-b } & 0.1 & $\mathrm{M}$ & 14 & 15.82 & 8.445 & 76.6225 & 4.33 & 98.88 \\
\hline & 0.1 & $\mathrm{~F}$ & 15 & 14.66 & 11.1411 & 94.1734 & 3.5 & 74.11 \\
\hline & 1 & $\mathrm{M}$ & 7 & 14.74 & 9.18426 & 60.5433 & 5.03 & 106.89 \\
\hline & 1 & $\mathrm{~F}$ & 9 & 13.4 & 9.92303 & 84.5505 & 3.86 & 74.56 \\
\hline & 10 & $\mathrm{M}$ & 5 & 14.45 & 16.9725 & 57.6311 & 5.97 & 124.38 \\
\hline & 10 & F & 10 & 13.78 & 16.8571 & 68.8351 & 4.5 & 89.5 \\
\hline & Mean & & & 14.48 & 12.0872 & 73.7260 & 4.53 & 94.72 \\
\hline & SE & & & 0.34 & 1.57 & 5.77 & 0.36 & 5.88 \\
\hline \multirow{8}{*}{ XA-c } & 0.1 & $\mathrm{M}$ & 14 & 16.17 & 8.87910 & 60.6509 & 5.39 & 125.66 \\
\hline & 0.1 & $\mathrm{~F}$ & 15 & 15.33 & 12.73490 & 73.7408 & 4.48 & 98.95 \\
\hline & 1 & $\mathrm{M}$ & 7 & 14.39 & 8.71959 & 50.8748 & 6.02 & 124.88 \\
\hline & 1 & F & 9 & 12.36 & 11.69086 & 71.4821 & 4.69 & 83.64 \\
\hline & 10 & $\mathrm{M}$ & 5 & 14.52 & 8.23345 & 44.0113 & 6.84 & 143.27 \\
\hline & 10 & $\mathrm{~F}$ & 10 & 13.68 & 9.17088 & 54.0151 & 5.88 & 116.08 \\
\hline & Mean & & & 14.41 & 9.90480 & 59.13 & 5.55 & 115.41 \\
\hline & $\mathrm{SE}$ & & & 0.54 & 0.69 & 4.38 & 0.33 & 7.91 \\
\hline
\end{tabular}

$\mathrm{Vc}=$ Volume of distribution of the Central Compartment, $\mathrm{CL}=$ Clearance, $\mathrm{C}_{\max }=$ maximum observed mean concentration, $\mathrm{AUC} \infty=$ Area under the curve from time $=0$ to infinity. 

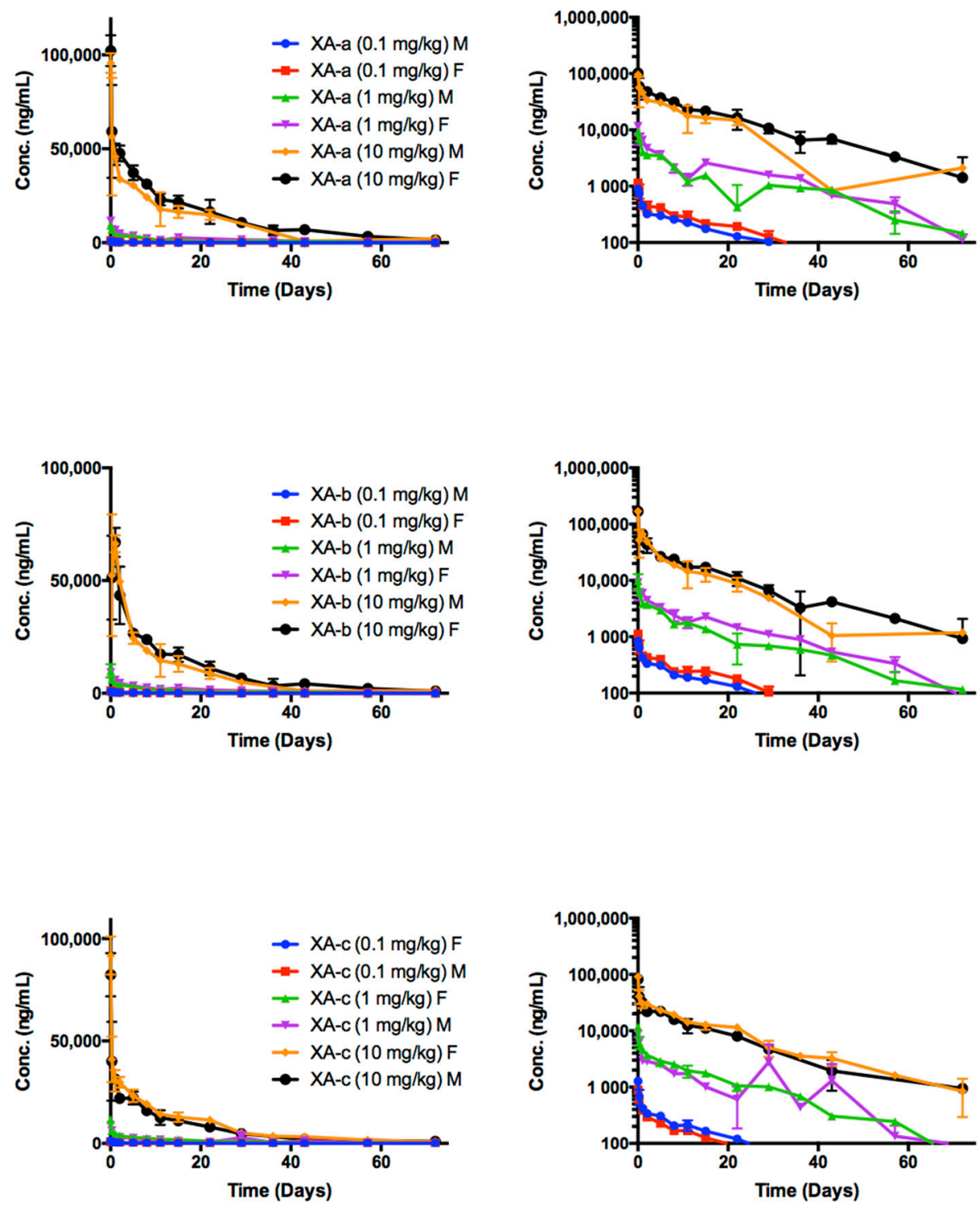

Figure 1. The time course of rat serum $m A b$ concentrations after single intravenous (IV) dose administration of NTM-1631. NTM-1631 component mAbs are denoted XA-a, XA-b, XA-c. The animals were dosed with a single IV bolus of $0.1,1.0$ and $10 \mathrm{mg} / \mathrm{kg}$ of drug product. Log concentration plots are shown on the right. The data presented are from rats negative for immunogenicity against drug only (no anti-drug antibodies (ADA), See Table S1). The points represent the mean \pm SE of $n=3$ or more.

Indicators of exposure, maximum concentration $\left(\mathrm{C}_{\max }\right)$ and area under the curve (AUC) values, increased approximately linearly with the dose for XA-a, XA-b, and XA-c as shown in Figure 2. Only the observed $C_{\max }$ for XA-b in the $10 \mathrm{mg} / \mathrm{kg}$ dose group was higher than the $C_{\max }$ for XA-a and XA-c. This resulted in a greater than linear increase in this parameter for XA-b. The $A U C_{\text {last }}$ for all three antibodies increased in a dose-dependent manner. Based on the $\mathrm{AUC}_{\text {last, }}$, exposure to each of the mAbs was higher in females than males. In both males and females, exposure was highest for XA-a, followed by XA-b and then XA-c based on AUC data. The AUC $C_{\infty}$ values were essentially the same as the $A U C_{\text {last }}$ values, as would be expected since serum samples were collected through 72 days after dose administration or approximately 5 half-lives. The volume of distribution of the central compartment $(\mathrm{Vc})$ values were similar for all three $\mathrm{mAbs}$ and all dose groups. The values varied from $69.58 \mathrm{~mL} / \mathrm{kg}$ (XA-a, $1 \mathrm{mg} / \mathrm{kg}$, females) to $125.88 \mathrm{~mL} / \mathrm{kg}$ (XA-c, $0.1 \mathrm{mg} / \mathrm{kg}$, males) suggesting distribution to the vascular space. The result for $\mathrm{Cl}$ tended to be slightly higher in male than female rats, for each 
$\mathrm{mAb}$ and dose level, as expected based on the slightly higher exposure observed for females relative to males.
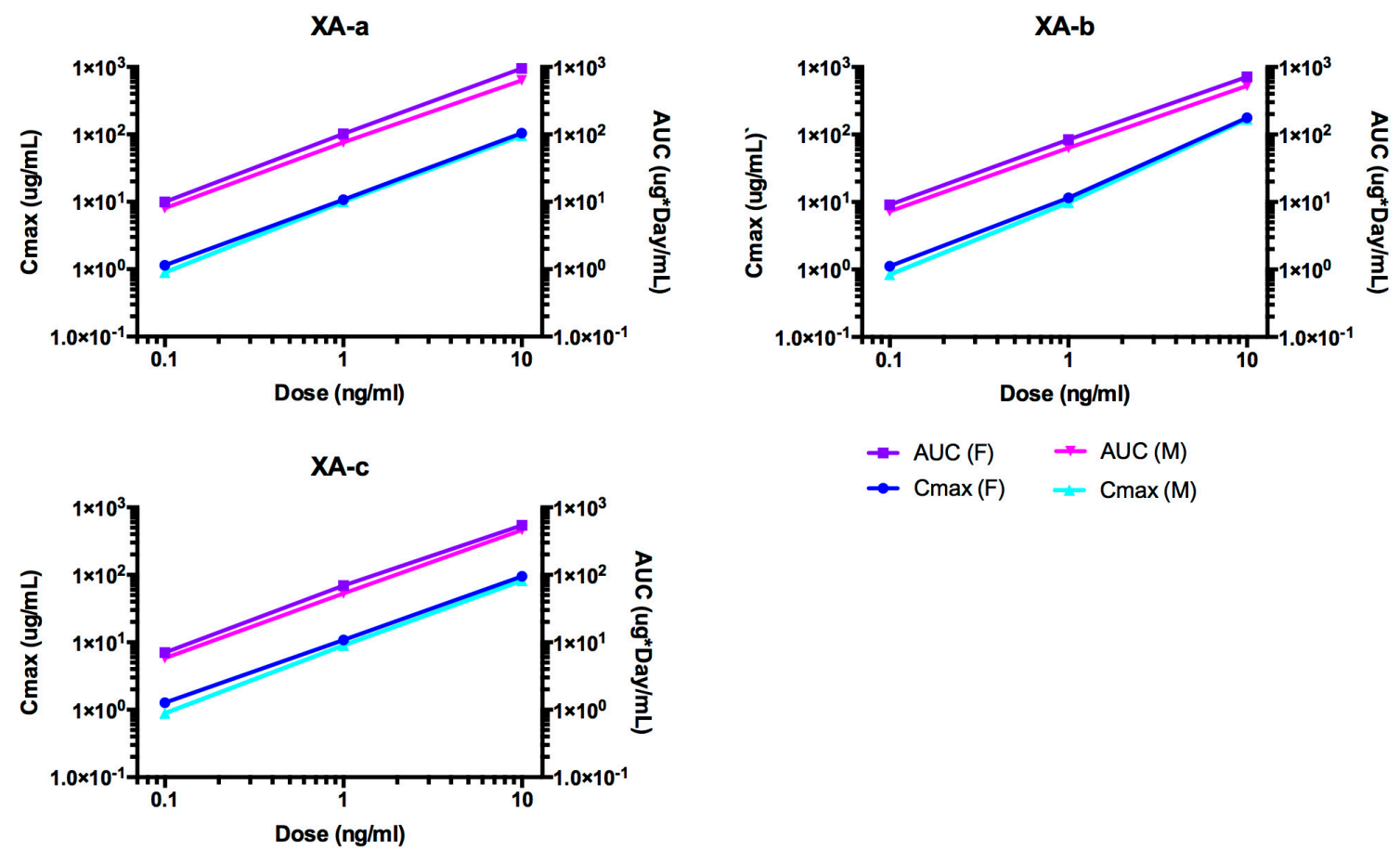

Figure 2. Dose-dependent $C_{\max }$ (maximum observed mean concentration) and AUC (area under the curve) of individual monoclonal antibodies (mAbs) for male and female rats after single IV administration of NTM-1631. The data presented are from rats with non-ADA only, see Table S1.

\subsection{ADA of NTM-1631}

An ADA response depends primarily on immunogenicity of the drug, dose frequency, and route. Human proteins are expected to be immunogenic to rats and did produce an ADA response in 30 of 90 NTM-1631-treated rats. At the lowest dose group $(0.1 \mathrm{mg} / \mathrm{kg})$, ADA were detected in only one animal. In the mid-dose group $(1 \mathrm{mg} / \mathrm{kg}), 47 \%$ of the animals $(8 / 15$ males and $6 / 15$ females) were ADA-positive and $50 \%$ in the high dose group $(10 \mathrm{mg} / \mathrm{kg})$ were ADA-positive (10/15 males and 5/15 females).

Antibodies against XA-a, XA-b, and XA-c in the serum were evaluated for the last time-point for each animal at the terminal blood collection (3 rats/sex/group at days 29, 36, 43, 57, and 71). In the low dose group, only one rat at a single timepoint elicited an antibody response to NTM-1631 (Table S1). The data from ADA-positive rats were not used in calculations of PK parameters.

\subsection{Pharmacokinetic Analyses NTM-1632}

The time course of NTM-1632 antibodies in rat sera are shown in Figure 3. NTM-1632 component $\mathrm{mAbs}$ are denoted XB-a, XB-b, XB-c. The PK parameters were calculated for ADA-negative animals in the study (Table 2). Indicators of exposure, $\mathrm{C}_{\max }$ and AUC values, increased approximately linearly with the dose for all three antibodies as shown in Figure 4 . The $\mathrm{C}_{\max }$ values were similar among dose levels for each of the three mAbs in NTM-1632. No sex differences were observed in the concentration at various times, thus data from male and female rats were pooled. Noncompartmental analyses demonstrated that all three $\mathrm{mAbs}$ displayed similar $\mathrm{T}_{1 / 2}$ ranging from: $\mathrm{XB}-\mathrm{a}, 13.6$ days $(10 \mathrm{mg} / \mathrm{kg}$, females) to 17.9 days $(0.1 \mathrm{mg} / \mathrm{kg}$, males); $\mathrm{XB}-\mathrm{b}, 9.15$ days $(0.1 \mathrm{mg} / \mathrm{kg}$, males) to 20.3 days $(0.1 \mathrm{mg} / \mathrm{kg}$, females); and XB-c 13.3 days (10 mg/kg, females) to 19.6 days ( $0.1 \mathrm{mg} / \mathrm{kg}$, males). Vc were similar for all three antibodies at all dose groups and tended to be lower in males than in females for all three mAbs, although the differences were small, suggesting distribution to the vascular space. The $\mathrm{Cl}$ values were 
also lower in males, which is consistent with the higher AUC observed in male rats. Note that in Figure 3, data points for the $0.1 \mathrm{mg} / \mathrm{kg}$ dose are overlapping in linear and logarithmic plots.
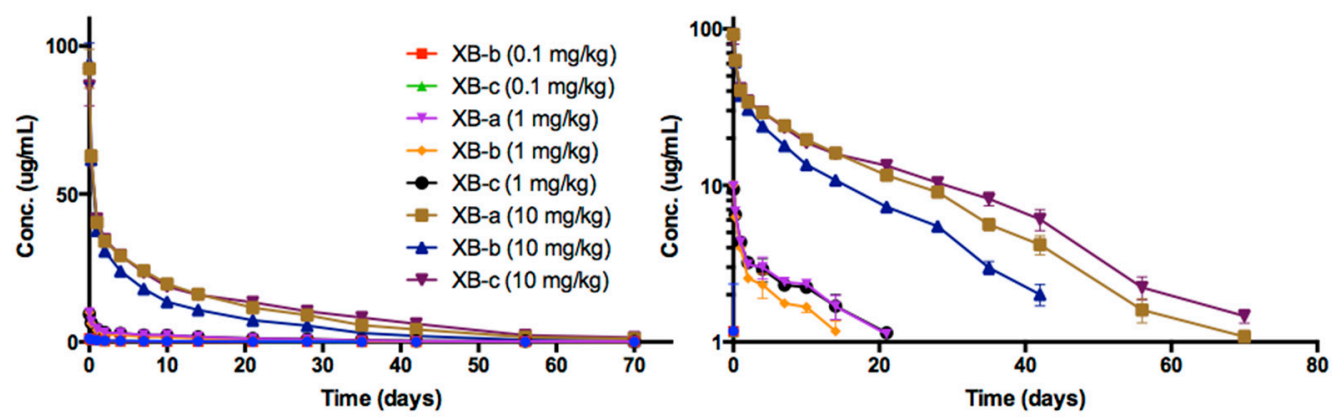

Figure 3. The time course of rat serum $\mathrm{mAb}$ concentrations after single IV dose administration of NTM-1632. NTM-1632 component mAbs are denoted XB-a, XB-b, XB-c. Animals were dosed with a single IV bolus of $0.1,1.0$ and $10 \mathrm{mg} / \mathrm{kg}$ of drug product. Log concentration plots are shown on the right. The data presented are from rats negative for immunogenicity against drug only (no ADA, See Table S1). The points represent the mean \pm SE of $n=3$ or more.

Table 2. Pharmacokinetic parameters of NTM-1632 for ADA-negative animals.

\begin{tabular}{|c|c|c|c|c|c|c|c|}
\hline Antibody & $\begin{array}{c}\text { Dose } \\
\mathrm{mg} / \mathrm{kg}\end{array}$ & Sex & $\mathrm{T}_{1 / 2}$ Day & $\begin{array}{c}C_{\max } / \text { Dose } \\
\mathrm{kg} \times \mu \mathrm{g} \\
/ \mathrm{mL} / \mathrm{mg}\end{array}$ & $\begin{array}{c}\text { AUC } \infty / \text { Dose } \\
\text { Day } \times \mathrm{kg} \times \mu \mathrm{g} \\
/ \mathrm{mL} / \mathrm{mg}\end{array}$ & $\begin{array}{c}\mathrm{CL} \\
\mathrm{mL} / \mathrm{kg} / \text { Day }\end{array}$ & Vc mL/kg \\
\hline \multirow{8}{*}{ XB-a } & 0.1 & M & 17.9 & 11.1 & 77.8 & 4.29 & 33.5 \\
\hline & 0.1 & F & 17.5 & 12.4 & 86 & 3.88 & 30.5 \\
\hline & 1 & $\mathrm{M}$ & 16 & 9.83 & 77.6 & 4.3 & 35.3 \\
\hline & 1 & $\mathrm{~F}$ & 15.1 & 9.92 & 62.4 & 5.35 & 37.5 \\
\hline & 10 & M & 14.7 & 9.865 & 72.8 & 4.59 & 36.4 \\
\hline & 10 & $\mathrm{~F}$ & 13.6 & 8.82 & 68.79 & 4.85 & 41.2 \\
\hline & Mean & & 15.9 & 10.32 & 74.23 & 4.54 & 35.73 \\
\hline & SE & & 1 & 1.25 & 8.18 & 0.51 & 3.63 \\
\hline \multirow{8}{*}{ XB-b } & 0.1 & $\mathrm{M}$ & 9.51 & 11 & 51.5 & 6.48 & 33.7 \\
\hline & 0.1 & F & 20.3 & 12.3 & 58.1 & 5.75 & 30.6 \\
\hline & 1 & $\mathrm{M}$ & 13.3 & 10.4 & 53.8 & 6.2 & 35.9 \\
\hline & 1 & $\mathrm{~F}$ & 14.2 & 9.71 & 42.1 & 7.94 & 38 \\
\hline & 10 & $\mathrm{M}$ & 11.7 & 10.035 & 49.49 & 6.75 & 36.6 \\
\hline & 10 & $\mathrm{~F}$ & 11.4 & 9.013 & 47.76 & 6.98 & 40.1 \\
\hline & Mean & & 13.40 & 10.41 & 50.46 & 6.68 & 35.82 \\
\hline & $\mathrm{SE}$ & & 3.75 & 1.14 & 5.45 & 0.75 & 3.33 \\
\hline \multirow{8}{*}{ XB-C } & 0.1 & $M$ & 19.6 & 10.5 & 79.3 & 4.21 & 34.9 \\
\hline & 0.1 & $\mathrm{~F}$ & 18.7 & 12.6 & 91.5 & 3.65 & 29.9 \\
\hline & 1 & M & 16.8 & 9.35 & 80.4 & 4.15 & 37.3 \\
\hline & 1 & $\mathrm{~F}$ & 16.7 & 9.59 & 65.4 & 5.11 & 39.1 \\
\hline & 10 & M & 13.7 & 8.995 & 79.16 & 4.22 & 40 \\
\hline & 10 & $\mathrm{~F}$ & 13.3 & 8.427 & 76.62 & 4.35 & 43.1 \\
\hline & Mean & & 16.47 & 9.91 & 78.73 & 4.28 & 37.38 \\
\hline & $\mathrm{SE}$ & & 2.56 & 1.49 & 8.35 & 0.47 & 4.57 \\
\hline
\end{tabular}

$\mathrm{C}_{\max }=$ Maximum observed mean concentration; $\mathrm{AUC} \infty$ = Area Under the Curve to infinity; $\mathrm{CL}=$ Clearance; $\mathrm{V}_{\mathrm{C}}=$ Volume of distribution of the central compartment.

\subsection{ADA of NTM-1632}

Only five out of the 90 rats were ADA-positive (Table S1). At the lowest dose group (0.1 mg/kg), only one animal was detected to be ADA-positive. In the middle dose group $(1 \mathrm{mg} / \mathrm{kg})$ and high dose group $(10 \mathrm{mg} / \mathrm{kg})$, two animals were ADA-positive from each group. By day 35 , most of the 
ADA-positive animals had serum concentrations of the mAbs that were at or near the lower limit of quantification (LLOQ) of the assay. The data from the ADA-positive animals from this study were not used in further calculations of the PK parameters.

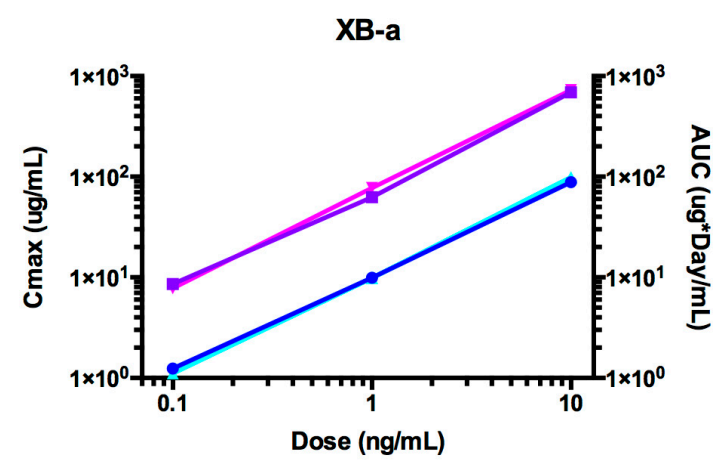

XB-C

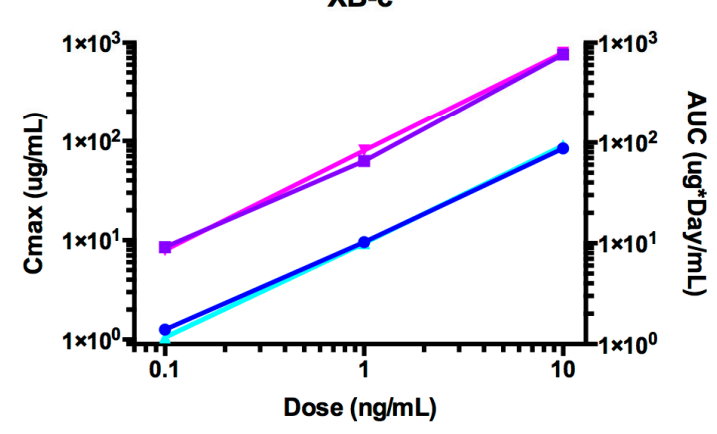

XB-b

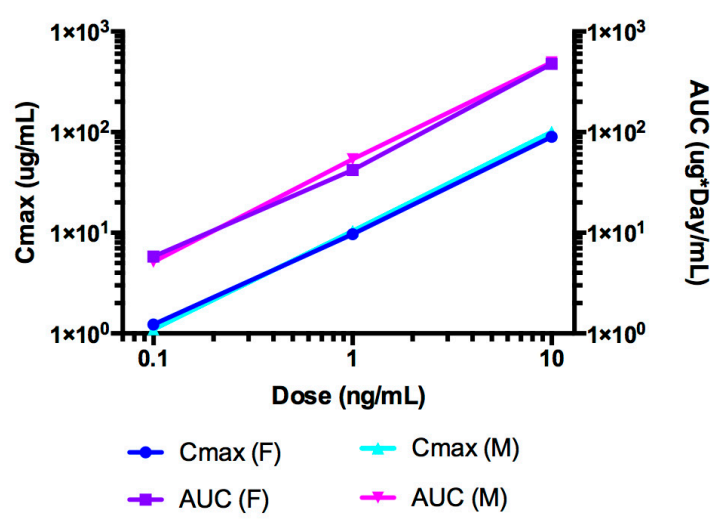

Figure 4. Dose-dependent $C_{\max }$ and AUC for rats after single IV administration of NTM-1632. The data presented are from rats with no ADA.

\subsection{Pharmacokinetic Analyses NTM-1633}

The time course of NTM-1633 antibodies in rat sera are shown in Figure 5. NTM-1633 component mAbs are denoted XE-a, XE-b, XE-c. The PK parameters were calculated for ADA-negative animals in the study (Table 3). The indicators of exposure, $C_{\max }$ and AUC values, increased approximately linearly with dose for all three antibodies as shown in Figure 6. The mean NTM-1633 antibody concentrations showed a biexponential decline in the time-concentration curve at each dose level $(0.1,1.0$, and $10 \mathrm{mg} / \mathrm{kg}$ ) and for each antibody (XE-a, XE-b, and XE-c). Noncompartmental analysis showed similar elimination half-lives between the antibodies XE-a and XE-b with overall mean values of 17.3 and 17.5 days, respectively, and a shorter overall mean half-life of 13.5 days for XE-c. Clearance varied among the antibodies with overall mean values of $4.21,7.58$, and $17.8 \mathrm{~mL} / \mathrm{day} / \mathrm{kg}$ for XE-a, $\mathrm{XE}-\mathrm{b}$, and XE-c, respectively. Exposure-based on AUC $\infty$ between antibodies was consistently greater for XE-a, followed by XE-b and then XE-c at each dose level, which is consistent with the trend that higher clearance lowers AUC. Overall, $\mathrm{C}_{\max }$ also showed linearity among all the dose levels within each antibody, except for the $0.1 \mathrm{mg} / \mathrm{kg} X \mathrm{XE}-\mathrm{a} \mathrm{C}_{\max }$, which showed greater than expected maximum concentration relative to its 1.0 and $10 \mathrm{mg} / \mathrm{kg}$ dose. Vc was similar for all three antibodies with an overall average of $35.1,38.1$, and $52.1 \mathrm{~mL} / \mathrm{kg}$ for XE-a, XE-b, and XE-c, respectively. No sex differences were observed in the concentration-time plots of each antibody. Therefore, because data points for male and female rats would overlap, data from male and female was pooled for these time plots. In Figure 5, data points for the lowest dose, $0.1 \mathrm{mg} / \mathrm{kg}$, are closely overlapping. 

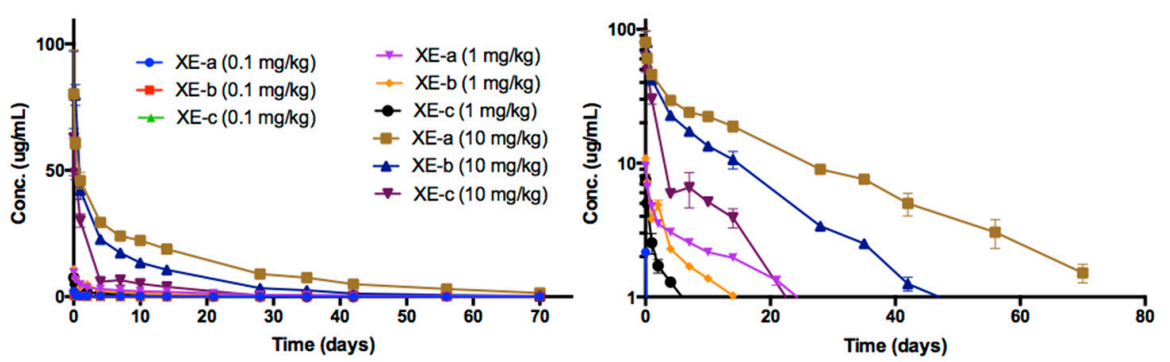

Figure 5. The time course of rat serum mAb concentrations after a single IV dose administration of NTM-1633. Animals were dosed with a single IV bolus of $0.1,1.0$ and $10 \mathrm{mg} / \mathrm{kg}$ of drug product. Log concentration plots are shown on the right. The data presented are from rats negative for immunogenicity against drug only (no ADA, See Table S1). Points represent the mean \pm SE of $n=3$ or more.

Table 3. Pharmacokinetic parameters of NTM-1633 for ADA-negative animals.

\begin{tabular}{|c|c|c|c|c|c|c|}
\hline Antibody & $\begin{array}{c}\text { Dose } \\
\mathrm{mg} / \mathrm{kg}\end{array}$ & $\mathbf{T}_{1 / 2}$ day & $\begin{array}{c}\mathrm{C}_{\max } / \text { Dose } \\
\mathrm{kg} \times \mu \mathrm{g} / \mathrm{mL} / \mathrm{mg}\end{array}$ & $\begin{array}{c}\text { AUC } \infty / \text { Dose } \\
\text { Day } \times \mathrm{kg} \times \mu \mathrm{g} / \mathrm{mL} / \mathrm{mg}\end{array}$ & $\begin{array}{c}\mathrm{CL} \\
\mathrm{mL} / \mathrm{kg} / \mathrm{day}\end{array}$ & $\mathrm{Vc} \mathrm{mL} / \mathrm{kg}$ \\
\hline \multirow{5}{*}{ XE-a } & 0.1 & 21.7 & 21.6 & 81.8 & 4.09 & 22.8 \\
\hline & 1 & 13.9 & 9.5 & 75.2 & 4.43 & 38.2 \\
\hline & 10 & 16.3 & 8.02 & 80.9 & 4.12 & 44.3 \\
\hline & Mean & 17.3 & 13.04 & 79.3 & 4.21 & 35.1 \\
\hline & SE & 2.3 & 4.3 & 2.1 & 0.11 & 6.4 \\
\hline \multirow{5}{*}{ XE-b } & 0.1 & 30.1 & 8.71 & 40.9 & 8.18 & 43.4 \\
\hline & 1 & 10.7 & 10.8 & 45.9 & 7.26 & 32.7 \\
\hline & 10 & 11.8 & 8.18 & 45.7 & 7.29 & 38.1 \\
\hline & Mean & 17.5 & 9.23 & 44.17 & 7.58 & 38.1 \\
\hline & $\mathrm{SE}$ & 6.3 & 0.8 & 1.63 & 0.3 & 3.1 \\
\hline \multirow{5}{*}{ XE-c } & 0.1 & 8.19 & 6.15 & 18.7 & 17.9 & 54.4 \\
\hline & 1 & 22.5 & 7.52 & 20.8 & 16 & 47.1 \\
\hline & 10 & 9.91 & 6.28 & 17.2 & 19.4 & 54.8 \\
\hline & Mean & 13.5 & 6.65 & 18.9 & 17.8 & 52.1 \\
\hline & SE & 4.5 & 0.44 & 1.04 & 1 & 2.5 \\
\hline
\end{tabular}

$\mathrm{C}_{\max }=$ Maximum observed mean concentration; $\mathrm{AUC} \infty=$ Area Under the Curve to infinity; $\mathrm{CL}=$ clearance; $\mathrm{Vc}=$ volume of distribution of the central compartment; $\mathrm{T}_{1 / 2}=$ half-life.

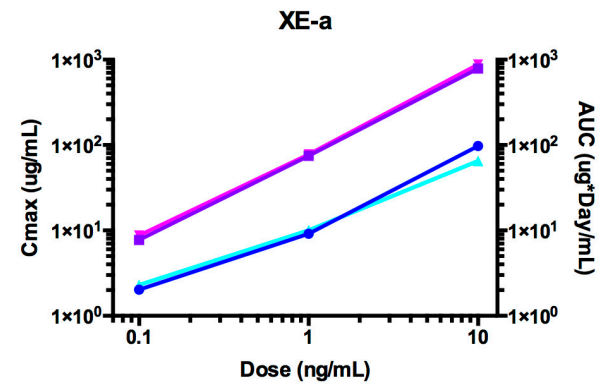

XE-c

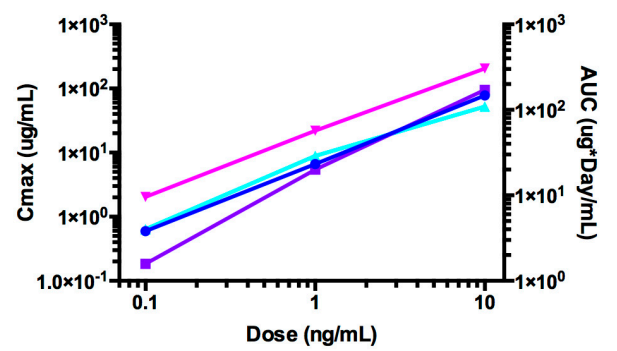

XE-b

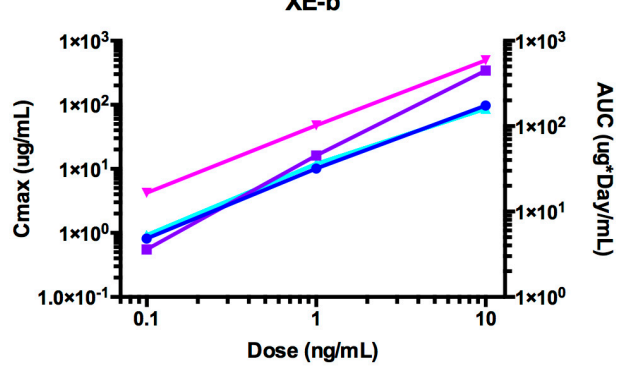

$\rightarrow \mathrm{AUC}(\mathrm{F}) \quad \mathrm{AUC}(\mathrm{M})$

$\rightarrow C \max (F) \simeq C \max (M)$

Figure 6. Dose-dependent $C_{\max }$ and AUC for rats after single IV administration of NTM-1633. The data presented are from rats with no ADA. 


\subsection{ADA of NTM-1633}

Twenty-six animals out of 90 rats were ADA-positive: seven (23.3\%) in the $1 \mathrm{mg} / \mathrm{kg}$ and 19 (63.3\%) in the $10 \mathrm{mg} / \mathrm{kg}$ dose groups, with no ADA in the $0.1 \mathrm{mg} / \mathrm{kg}$ dose group (Table S1). Clearance from all ADA-positive animals for each antibody increased relative to the animals testing ADA-negative. By Day 42, most ADA-positive animals had mAb concentrations at or near the LLOQ of the assay.

\subsection{Pharmacokinetic Analyses NTM-1634}

The time course of NTM-1634 antibodies in rat sera are shown in Figure 7. NTM-1634 component mAbs are denoted by XCD-a, XCD -b, XCD -c, XCD-d. The PK parameters were calculated for ADA-negative animals in the study (Table 4). Indicators of exposure, $C_{\max }$ and AUC values, increased approximately linearly with the dose for all three antibodies as shown in Figure 8 . The $\mathrm{T}_{1 / 2}$ was approximately 7 to 10 days for the lowest dose for four NTM-1634 antibodies. The 1 and $10 \mathrm{mg} / \mathrm{kg}$ dose groups had half-lives of 9 to 10 days for these same antibodies. All four antibodies had a similar response for all dose groups as shown in Figure 1. XCD-a antibody showed a more rapid clearance profile than the other antibodies at all three doses. The other three antibodies had a similar response for all three doses.
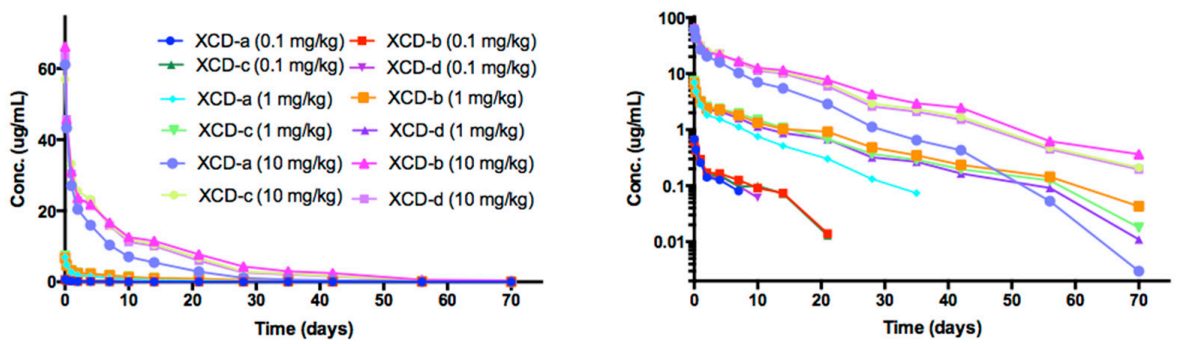

Figure 7. The time course of rat serum mAb concentrations after single IV dose administration of NTM-1634. The animals were dosed with a single IV bolus of $0.1,1.0$ and $10 \mathrm{mg} / \mathrm{kg}$ of drug product. Log concentration plots are shown on the right. The data presented are from rats negative for immunogenicity against drug only (no ADA, See Table S1). The points represent the mean \pm SE of $\mathrm{n}=3$ or more.

Table 4. Pharmacokinetic parameters of NTM-1634 for ADA-negative animals.

\begin{tabular}{|c|c|c|c|c|c|c|}
\hline Antibody & $\begin{array}{l}\text { Dose } \\
\mathrm{mg} / \mathrm{kg}\end{array}$ & $\begin{array}{l}T_{1 / 2} \\
\text { day }\end{array}$ & $\begin{array}{c}C_{\max } / \text { Dose } \\
\mu \mathrm{g} \times \mathrm{kg} / \mathrm{mL} / \mathrm{mg}\end{array}$ & $\begin{array}{c}\text { AUC } \infty / \text { Dose } \\
\text { Day } \times \mathrm{kg} \times \mu \mathrm{g} / \mathrm{mL} / \mathrm{mg}\end{array}$ & $\begin{array}{c}\mathrm{CL} \\
\mathrm{mL} / \mathrm{day} / \mathrm{kg}\end{array}$ & $\begin{array}{c}\mathrm{Vc} \\
\mathrm{mL} / \mathrm{kg}\end{array}$ \\
\hline \multirow{3}{*}{ XCD-a } & 0.1 & 5.19 & 6.75 & 19.2 & 53.4 & 373 \\
\hline & 1 & 7.58 & 6.96 & 25.5 & 39.2 & 429 \\
\hline & 10 & 7.47 & 6.16 & 25.4 & 39.4 & 425 \\
\hline Mean & & 6.747 & 6.62 & 23.37 & 44.00 & 409.00 \\
\hline \multirow[t]{2}{*}{$\mathrm{SE}$} & & 1.349 & 0.41 & 3.61 & 8.14 & 31.24 \\
\hline & 0.1 & 7.57 & 6.10 & 29.6 & 34.6 & 370 \\
\hline \multirow[t]{2}{*}{ XCD-b } & 1 & 11.6 & 6.77 & 49.7 & 20.2 & 338 \\
\hline & 10 & 11.1 & 6.56 & 49.0 & 20.4 & 328 \\
\hline Mean & & 10.090 & 6.48 & 42.77 & 25.07 & 345.33 \\
\hline \multirow[t]{2}{*}{$\mathrm{SE}$} & & 2.197 & 0.34 & 11.41 & 8.26 & 21.94 \\
\hline & 0.1 & 10.8 & 6.52 & 32.1 & 32.7 & 461 \\
\hline \multirow[t]{2}{*}{ XCD-c } & 1 & 10.1 & 7.34 & 47.5 & 21.1 & 307 \\
\hline & 10 & 10.2 & 5.71 & 44.5 & 22.5 & 331 \\
\hline Mean & & 10.367 & 6.52 & 41.37 & 25.43 & 366.33 \\
\hline \multirow[t]{2}{*}{$\mathrm{SE}$} & & 0.379 & 0.82 & 8.16 & 6.33 & 82.86 \\
\hline & 0.1 & 7.3 & 6.55 & 24.5 & 45.8 & 386 \\
\hline \multirow[t]{2}{*}{ XCD-d } & 1 & 9.6 & 7.42 & 41.7 & 24.0 & 335 \\
\hline & 10 & 9.9 & 6.31 & 42.2 & 23.7 & 338 \\
\hline mean & & 8.933 & 6.76 & 36.13 & 31.17 & 353 \\
\hline $\mathrm{SE}$ & & 1.422 & 0.58 & 10.08 & 12.67 & 28.62 \\
\hline
\end{tabular}

$\mathrm{C}_{\max }=$ Maximum observed mean concentration; $\mathrm{AUC} \infty \mathrm{O}=$ Area Under the Curve to infinity; $\mathrm{CL}=$ clearance; $\mathrm{V}_{\mathrm{C}}=$ volume of distribution of the central compartment; $\mathrm{T}_{1 / 2}=$ half-life. 
XCD-a

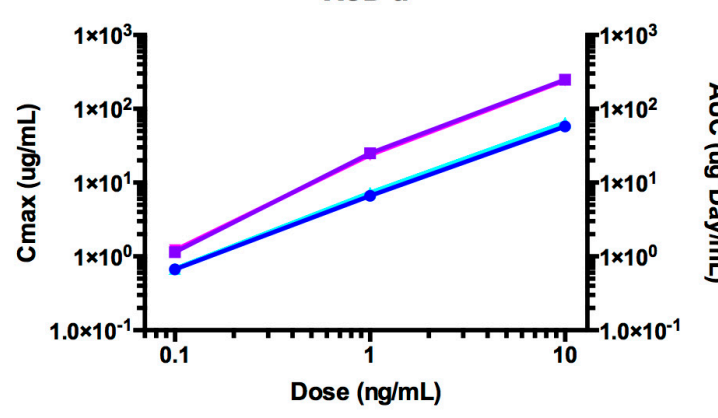

XCD-c

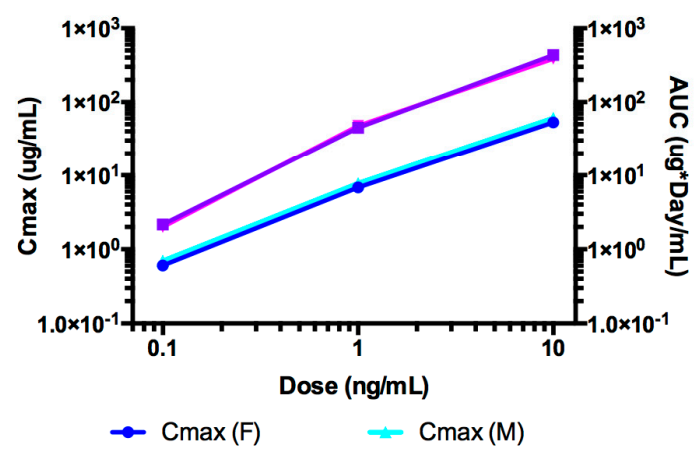

XCD-b

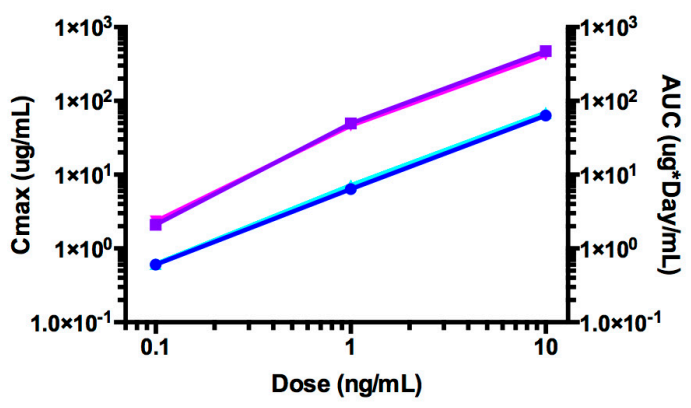

XCD-d

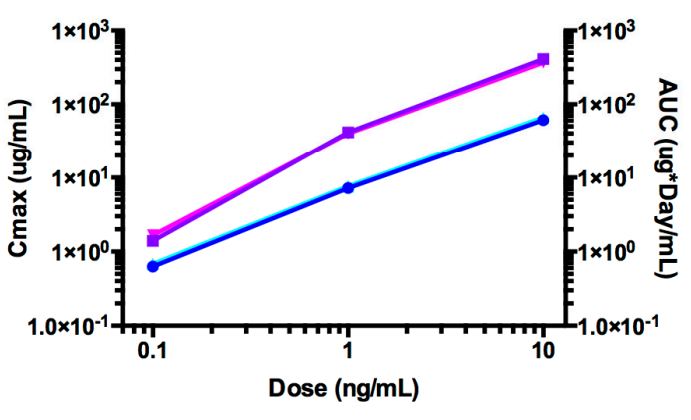

$\rightarrow \operatorname{AUC}(\mathrm{F}) \quad \underset{(\mathrm{M})}{\mathrm{AUC}}$

Figure 8. Dose-dependent $C_{\max }$ and AUC for rats after single IV administration of NTM-1634. The data presented are from rats with no ADA.

The $\mathrm{T}_{1 / 2}$ for the XCD-a was approximately $30 \%$ less than the other three antibodies across the three dose groups and showed a more rapid clearance profile for all dose groups. Observed antibody clearance profiles are typical for rats injected with human antibodies. Vc values were similar for all four antibodies at all dose groups.

\subsection{ADA of NTM-1634}

Nineteen out of the 108 rats were ADA-positive (Table S1). At the lowest dose group $(0.1 \mathrm{mg} / \mathrm{kg})$, three animals were confirmed to be ADA-positive. In the middle dose group $(1 \mathrm{mg} / \mathrm{kg})$ and high dose group (10 mg/kg), 14 animals were ADA-positive from each group. By day 35, most of the ADA-positive animals had serum concentrations of the mAbs that were at or near the LLOQ of the assay. The presence of ADA in some of the animals did not significantly affect the PK as the difference between the PK parameters with and without ADA animals was not significantly different. In Figure 7 , data points for the lowest does, $0.1 \mathrm{mg} / \mathrm{kg}$ are overlapping.

\subsection{Relationship of Half-Life and Clearance to $p I$}

Each of the 13 IgG1 antibodies studied here has the same constant region, with different variable regions. It was therefore considered whether $\mathrm{pI}$ was correlated with clearance and $\mathrm{T}_{1 / 2}$ as previously reported for IgG4 antibodies [29]. It was found that predicted pI was uncorrelated with half-life ( $\mathrm{r}$ squared $=0.0036$, data not shown).

\section{Discussion}

Botulinum neurotoxins are among the most toxic known compounds [30], yet there is no preventive agent for botulism that would be logistically feasible should large numbers of people be exposed to BoNT via either food or intentional exposure by those of ill intent. Next generation recombinant human antitoxins for BoNTs are in clinical development, funded by NIAID. These recombinant antibody-based 
drugs address the many drawbacks of equine antitoxin (BAT) [21], namely, adverse events due to immunogenicity of non-human antibodies, lack of lot-to-lot reproducibility, high cost of goods, and a short half-life. These recombinant antibodies could also replace the human-derived immune globulin antitoxin (BabyBIG) [20], for which future production is in jeopardy due to lack of an approved human vaccine [31].

Any prophylactic or therapeutic treatment for botulism due to food poisoning should have an extended half-life in humans because colonization of the gut by clostridial species would produce toxins continuously, and a long half-life would allow prophylactic use of antibodies. Furthermore, an extended half-life allows for prophylactic use of antitoxins, should potential exposure to toxins be anticipated, such as in the case of emergency responders or military personnel. The short half-life of BAT precludes its use for prevention of botulism, since protective serum levels of antibody are short lived, on the order of hours to 0.33 to 2 days [21]. This study provides the PK parameters of NTM-1631, NTM-1632, NTM-1633 and NTM-1634 administered IV in rats.

With respect to safety in rats, administration of these human recombinant antibody drug products by slow bolus IV injection was well tolerated in Sprague Dawley rats at levels up to $10 \mathrm{mg} / \mathrm{kg} / \mathrm{dose}$, being the highest dose for these studies. Rats showed no significant changes in clinical findings, serum chemistry, hematology, urinalysis, or histopathology at a dose of $50 \mathrm{mg} / \mathrm{kg}$ delivered IV for any of the four antitoxins. The escalating doses of each were well tolerated with no adverse effects that were drug specific. The safety of these antitoxins in humans so far, reflects that observed in rats, namely that no significant treatment associated adverse effects were observed [24], and unpublished results.

As these are human antibodies, ADA were expected and observed in rats. ADA-positive animals were more prevalent in the mid and high dose groups compared to the low dose group. The drugs were cleared from serum more rapidly with a shorter $\mathrm{T}_{1 / 2}$ and lower volume of distribution.

Previous studies have shown that the effectiveness of mAbs in neutralizing BoNTs is dependent on the presence of three antibodies against each BoNT [17]. The duration of the effectiveness of the combination may be determined when the level of a single antibody drops below the effective dose levels most rapidly. In human studies, the humanized mouse mAb was cleared most rapidly at the lowest dose, but all three mAbs comprising NTM-1631 were detected for a minimum of 4 weeks after infusion [24]. In the present study, all mAbs in each of the four drug products were detected up to 72 days after infusion. Similarly, PK results in a guinea pig model demonstrated that after IV injection, $\mathrm{mAb}$ concentrations were able to show protection in a mouse neutralization assay up to 14 days post injection [32].

The PK behavior of the individual antibody components of the four drug products (NTM-1631, NTM-1632, NTM-1633, NTM-6134) show a biphasic decline similar to other monoclonal antibodies. Each antibody exhibited dose-dependent exposure and long elimination half-lives of at least 7 days after IV administration of $0.1,1$, and $10 \mathrm{mg} / \mathrm{kg}$ in Sprague Dawley rats. Rat half-life was largely predictive of the rank order of half-life observed in humans. For NTM-1631, the rank order in rats and humans was XA-c > XA-b > XA-b [24] and for NTM-1634, the rank order in both rats and humans was XCD-b $>$ XCD-c $>$ XCD-d $>$ XCD-a (Snow et al., manuscript submitted). In rats, the most rapidly cleared $\mathrm{mAbs}$ are $\mathrm{XA}-\mathrm{c}\left(\mathrm{T}_{1 / 2} 12.7 \pm 2.8\right.$ days), $\mathrm{XB}-\mathrm{b}\left(\mathrm{T}_{1 / 2} 14.9 \pm 2.3\right.$ days), $\mathrm{XCD}-\mathrm{a}\left(\mathrm{T}_{1 / 2} 6.5 \pm 2\right.$ days), and XE-c ( $\mathrm{T}_{1 / 2} 13.5 \pm 4.5$ days).

Previous studies have demonstrated that the oligoclonal recombinant antibody antitoxins reduced the mortality in mice when administered prior to BoNT challenge [17,33-36], and post-challenge in mice [37]. Finally, NTM-1631 and NTM-1632 have been shown to protect guinea pigs from challenge with inhaled BoNT when the antibodies were administered prior to challenge [32].

\section{Conclusions}

Rat PK studies of the four antitoxins (NTM-1631, NTM-1632, NTM-1633, NTM-6134) were used to support investigational new drug (IND) applications to the FDA and to guide design of first in human studies. 


\section{Materials and Methods}

All studies were performed in accordance with the U.S. FDA "Good Laboratory Practice for Nonclinical Laboratory Studies" (GLP) as described in 21 CFR Part 58. All procedures were approved by the Animal Ethics Committees of SRI, protocol B311-08 (single dose PK protocol approved 15 July 2008) for NTM-1631; and Charles River Laboratory single-dose PK protocol 20021165 (approved 22 April 2013), multi-dose toxicology protocol 20021158 (approved 23 October 2013), for NTM-1632; single-dose PK protocol 20022284 (approved 15 April 2013), multi-dose toxicology study 20022285 (approved 23 October 2013) for NTM-1633; and dose finding toxicology protocol 20066727 (approved 26 May 2015), single dose PK study 20074281 (approved 26 May 2015), multi-dose toxicology 20081234 (approved 2 September 2015) for NTM-1634.

\subsection{Preparation of Test Articles}

All four antitoxins are composed of equimolar mixtures of three or four monoclonal antibodies (mAbs). NTM-1631 is composed of two human and one humanized mAbs (XA-a, XA-b, XA-c). NTM-1632 is composed of three human mAbs (XB-a, XB-b, XB-c), NTM-1633 composed of three human mAbs (XE-a, XE-b, XE-c) and NTM-1634 composed of four human mAbs (mAb XCD-a, XCD-b, XCD-c, XCD-d). Concentration of mAbs in each product was $5 \mathrm{mg} / \mathrm{mL}$ for NTM-1631 and NTM-1632, $5.1 \mathrm{mg} / \mathrm{mL}$ for NTM-1633 and NTM-1634. All test articles were stored at $4{ }^{\circ} \mathrm{C}$ until use. Test articles were prepared by dilution using $10 \mathrm{mM}$ sodium succinate/succinic acid and $142 \mathrm{mM} \mathrm{L}$-arginine-HCl and $0.005 \%$ polysorbate $80, \mathrm{pH} 6.0$, and were diluted and mixed for $20 \mathrm{~min}$ and then stored on wet ice prior to dose administration. Diluted test articles were prepared fresh on the day of dosing and brought to room temperature prior to administration to the animals. Formulation accuracy was verified by ELISA.

\subsection{Animal Care}

The study included male and female Sprague Dawley rats (Harlan Laboratories, Indianapolis, IN) for the NTM-1631 studies, and (Charles River Laboratories, Hollister, CA, USA) for the NTM-1632, NTM-1633 and NTM-1634 studies. Rats were divided into groups each with 15 male and 15 female rats (or 18 each male and female for the NTM-1634 study). The total number of rats for the entire study was 378 (90 each for NTM -1631, NTM-1632, NTM-1633 and 108 for NTM-1634). Male rats were 7.5 to 11 weeks of age and weighed 221-350 g. Female rats were 8.5 to 11 weeks of age and weighed 171-275 g. The dose administration schedule and study endpoints were clinical observations, body weights, and PK analysis by electrochemiluminescence (ECL).

General procedures for animal care and housing were in accordance with the National Research Council (NRC) Guide for the Care and Use of Laboratory Animals (1996) and the Animal Welfare Standards Incorporated in 9 CFR Part 3, 1991, and conformed to the testing facility SOPs. Animals were received and quarantined for 3-5 days during which time they were examined by a veterinarian, who assessed their health for suitability for use on-study. Animals were housed three or fewer per cage during quarantine and during the study in suspended polycarbonate cages (with bedding) on stainless steel racks. Rats were provided water and certified diet ad libitum.

All animals were euthanized with an overdose of sodium pentobarbital administered intraperitoneally after the last blood collection. The lack of heart beat was used to establish death. This method is acceptable according to the American Veterinary Medical Association Guidelines for Euthanasia [38].

\subsection{Dose Administration}

The animals were dosed by a single IV injection of $0.1,1$ or $10 \mathrm{mg} / \mathrm{kg} / \mathrm{dose}$ into the lateral tail vein over $\sim 45-60$ s once on Day 1 . The dosing volume was $2 \mathrm{~mL} / \mathrm{kg}(10 \mathrm{mg} / \mathrm{kg})$ based on the most recent body weights. The animals were temporarily restrained for dose administration and were not sedated. 


\subsection{Clinical Observations}

Observations for mortality and moribundity were performed at least daily. Pre-test cage-side observations for general health were conducted on all animals twice daily. Cage-side clinical observations for morbidity were conducted at least twice on days of dose administration (once before dose administration and at a target time of 1-h following dose administration) and at least once daily on the days without dose administration.

\subsection{Blood Sample Collection}

Blood samples were collected and processed for serum drug levels at pre-dose, $5 \mathrm{~min}, 6,24$, and $48 \mathrm{~h}$ post-dose and once on days $5,8,11,15,22,29,36,43,57$ and 71 or 72 . Three rats per sex were evaluated for each time-point. Blood was collected from the retro-orbital sinus of rats under $60: 40 \% \mathrm{CO}_{2}: \mathrm{O}_{2}$ anesthesia or from the jugular (preferred) or lateral tail vein from rats under anesthesia. Whole blood (target volume of $1 \mathrm{~mL}$ ) samples were collected into tubes with no anticoagulant, allowed to clot for $30 \mathrm{~min}$ at room temperature, and centrifuged $(1750 \times \mathrm{g})$ for $15 \mathrm{~min}$ at $2{ }^{\circ} \mathrm{C}-8{ }^{\circ} \mathrm{C}$ to yield serum. Each serum sample was divided into 2-3 aliquots, frozen on dry ice and then stored at $-80^{\circ} \mathrm{C}$ until testing.

Terminal sampling of whole blood (target minimum of $6 \mathrm{~mL}$ ) was collected from the cranial vena cava or other suitable peripheral vessel and processed as above. Before each blood collection, the animals were anesthetized using isoflurane (target $5 \%$ ) via inhalation. The animals were sacrificed using an overdose of sodium pentobarbital after terminal blood collection.

\subsection{Body Weights}

Individual body weights were recorded for all animals during the pre-test period for group assignment and dose-volume calculation.

\subsection{Serum Concentration for Pharmacokinetic Analysis}

Serum samples were analyzed for each individual monoclonal antibody (mAb) using ECL immunoassays on the Meso Scale Discovery (MSD, Gaithersburg, MD, USA) platform. Individual assays were used to measure the concentration of antibody in rat serum. Each antibody was measured using individual domains that bound only one antibody in the drug product. Biotinylated and ruthenylated domains were used directly. Standards and Quality Control samples (QCs) were prepared by spiking known amounts of antibody combination drug into rat serum. The stock calibration standard, quality control samples (QCs), and study samples were diluted in assay dilution buffer (ADB) at the minimum required dilution. The initial diluted stock calibration standard was further serially diluted using Sample Dilution Buffer (SDB) (ADB containing 5\% $(v / v), 2 \%(v / v)$, or 10\% $(v / v)$ rat serum-depending on the assay) to generate a calibration curve. Samples that required higher dilution were diluted using SDB before analysis.

For the XA-a assay, the domain was directly coated to an MSD plate, and then blocked with Blocking Buffer (phospho buffered saline (PBS) containing 3\% w/v bovine serum albumin). For the XA-b assay, biotin-domain conjugate was added to blocked MSD streptavidin plates. The standards, QCs and samples were diluted, added to the plates and incubated on a plate shaker at room temperature. After incubation, for the XA-a and XA-b assays, ruthenium conjugated secondary anti-human antibody was added, incubated and shielded from light.

For the XCD-a, XCD-c, and XCD-d assays, biotinylated domain was added to streptavidin plates. After incubation and blocking, standards, QCs, study samples and ruthenylated domain were added and incubated shielded from light.

For the $\mathrm{XA}-\mathrm{c}, \mathrm{XB}, \mathrm{XE}$ and $\mathrm{XCD}-\mathrm{b}$ assays, a solution of reaction mixture (biotinylated and ruthenylated domains plus standards, QCs or study samples) was incubated at room temperature on a plate shaker and shielded from light. After the initial incubation, the reaction mixture was loaded to 
a blocked, MSD streptavidin-coated plate and incubated at room temperature on a shaker shielded from light.

For all assays, after incubations and the addition of proprietary MSD Read Buffer, a chemiluminescent signal was generated when an electric current was applied and was detected for all wells using an MSD Sector Imager Instrument. The resulting signal was measured in ECL units, and the concentrations of antibodies were interpolated from the calibration curve.

\subsection{Immunogenicity}

Serum samples were evaluated for the presence of rat anti-human anti-drug antibodies (ADA) to each of the antibodies for each animal using an ECL assay. For the assay, a mixture of biotinylated or ruthenium conjugated antibodies was prepared in ADB and added to each well of a 96-well polypropylene plate. Diluted samples were transferred to the plates containing the labeled antibodies and incubated on a plate shaker. MSD streptavidin-coated plates were blocked with a blocking buffer. Following incubation, the blocked streptavidin-coated plates were washed three times in Wash Buffer (PBS containing $0.05 \%$ v $/ v$ Tween-20). The incubated mixtures were transferred to the washed blocked streptavidin plates and incubated at room temperature on a plate shaker shielded from the light. The streptavidin plates were washed three times in Wash Buffer. After washing, MSD Read Buffer was added to each well. ECL signals were determined for all wells using an MSD Sector Imager Instrument. The assay cut point was calculated for each plate by adjusting the normal control serum from each plate with a correction factor. Samples with an ECL signal greater than the assay cut-point were reported as positive.

Screened positive samples were further tested in the competitive confirmation assay with and without antibody. All assay procedures were the same as described above except the sample preparation procedure. Quality control and study samples were initially diluted 1:5 in ADB. To generate the 1:10 diluted samples without drugs, an aliquot of each the 1:5 diluted samples was mixed with an equal volume of ADB. To generate the 1:10 diluted samples with drugs, a separate aliquot of the same 1:5 diluted samples was mixed with equal volume of $\mathrm{ADB}$ containing the drug $\mathrm{mAbs}$ for a final dilution of 1:10 with the drug. The diluted samples were then incubated at $37^{\circ} \mathrm{C}$ for $1 \mathrm{~h}$. All subsequent sample incubation and sample analysis on MSD Sector Imager Instrument procedures were the same as in the screening assay. Percent Inhibition (\%INH) was calculated for all samples using the formula, $\% \mathrm{INH}=[1-$ (sample with drug/sample without drug) $] \times 100 \%$. Samples with \%INH greater than the confirmation cut point were reported as positive for the presence of anti-mAb antibodies and further analyzed using the titer assay described below. Samples with \%INH at or below the confirmation cut point were reported as negative.

All ADA-positive samples from all assays were further analyzed for titer determination using the ECL assay described above. Study samples were diluted 1:10 using ADB to generate the first dilution of the titration curve. Diluted samples were then diluted using SDB. The reported end-point titer was determined by performing linear regression using the two points flanking the signal intercept. The plate-specific cut-point was used as the signal intercept.

\subsection{Pharmacokinetic Analysis}

Non-compartmental PK analyses were performed on the serum concentration-time data to calculate $T_{1 / 2}, C_{\max }$, area under the serum concentration curve (AUC), the apparent volume of distribution $(\mathrm{V})$, and clearance $(\mathrm{Cl})$. All serum concentrations that were less than the LLOQ after the first measurable concentration were excluded from further calculations. Terminal elimination half-life values were determined from the slope of the line in the terminal elimination phase of the serum concentration-time curve. The $\mathrm{T}_{1 / 2}$ values and other terminal phase parameters were not reported if the $r$-value of the best-fit line was $<0.8$. A minimum of three time-points in the terminal phase were required for the calculation of $\mathrm{T}_{1 / 2}$. 
Supplementary Materials: The following are available online at http://www.mdpi.com/2072-6651/11/6/345/s1, Table S1: Numbers of ADA-positive animals.

Author Contributions: M.T.T. secured funding, conceived, and designed the experiments, analyzed data, Y.E., A.A., K.D., D.W., Z.M. conceived, designed, and performed the experiments, and analyzed the data; and R.R.C. wrote the paper; S.F.-J. visualized the data, and S.F.-J and J.D.M. edited the paper and secured funding.

Funding: This work was supported by contracts (HHSN266200600011C, HHSN272200800028C and HHSN272201100031C) from the National Institute of Allergy and Infectious Disease (NIAID), PI, M. Tomic. Opinions, interpretations, conclusions, and recommendations are those of the authors and not necessarily endorsed by NIAID.

Conflicts of Interest: M.T.T., Y.E., R.R.C., and D.W. are employees of Ology Bioservices, the company developing the antibodies described in this paper. The other others have no conflicts to disclose. The funding sponsors had no role in the design of the study; in the collection, analyses, or interpretation of data; in the writing of the manuscript, and in the decision to publish the results.

\section{References}

1. Hatheway, C.L. Botulism: The Present Status of the Disease. Curr. Top. Microbiol. Immunol. 1995, 195, 55-75. [PubMed]

2. Schiavo, G.; Benfenati, F.; Poulain, B.; Rossetto, O.; De Laureto, P.P.; DasGupta, B.R.; Montecucco, C. Tetanus and Botulinum-B Neurotoxins Block Neurotransmitter Release by Proteolytic Cleavage of Synaptobrevin. Nature 1992, 359, 832-835. [CrossRef] [PubMed]

3. Simpson, L.L. Identification of the Major Steps in Botulinum Toxin Action. Annu. Rev. Pharmacol. Toxicol. 2004, 44, 167-193. [CrossRef] [PubMed]

4. Sobel, J. Botulism. Clin. Infect. Dis. 2005, 41, 1167-1173. [CrossRef] [PubMed]

5. Hibbs, R.G.; Weber, J.T.; Corwin, A.; Allos, B.M.; Abd El Rehim, M.S.; Sharkawy, S.E.; Sarn, J.E.; McKee, K.T., Jr. Experience with the Use of an Investigational $\mathrm{F}\left(\mathrm{ab}^{\prime}\right) 2$ Heptavalent Botulism Immune Globulin of Equine Origin During an Outbreak of Type E Botulism in Egypt. Clin. Infect. Dis. 1996, 23, 337-340. [CrossRef] [PubMed]

6. Jalava, K.; Selby, K.; Pihlajasaari, A.; Kolho, E.; Dahlsten, E.; Forss, N.; Backlund, T.; Korkeala, H.; Honkanen-Buzalski, T.; Hulkko, T.; et al. Two Cases of Food-Borne Botulism in Finland Caused by Conserved Olives, October 2011. Eurosurveillance 2011, 16, 20034. [CrossRef]

7. Liu, Z.; Zhang, C.; Li, Y.; Song, C.; Sun, Y.; Wei, Y.; Xu, Z.; Yang, A.; Xu, Z.; Yang, K.; et al. High Sensitivity ELISA for Detection of Botulinum Neurotoxin Serotype F. Hybridoma 2012, 31, 233-239. [CrossRef]

8. Pingeon, J.M.; Vanbockstael, C.; Popoff, M.R.; King, L.A.; Deschamps, B.; Pradel, G.; Dupont, H.; Spanjaard, A.; Houdard, A.; Mazuet, C.; et al. Two Outbreaks of Botulism Associated with Consumption of Green Olive Paste, France, September 2011. Eurosurveillance 2011, 16, 20035. [CrossRef]

9. Rosen, O.; Ozeri, E.; Barnea, A.; David, A.B.; Zichel, R. Development of an Innovative in Vitro Potency Assay for Anti-Botulinum Antitoxins. Toxins 2016, 8, 276. [CrossRef]

10. Demarchi, J.; Mourgues, C.; Orio, J.; Prevot, A.R. Existence Du Botulisme De Type D. Bull. Acad. Nat. Med. 1958, 142, 580-582.

11. Prevot, A.R.; Terrasse, J.; Daumail, J.; Cavaroc, M.; Riol, J.; Sillioc, R. Existence En France Du Botulisme Humain De Type C. Bull. Acad. Med. (Paris) 1955, 139, 355-358.

12. Oguma, K.; Yokota, K.; Hayashi, S.; Takeshi, K.; Kumagai, M.; Itoh, N.; Tachi, N.; Chiba, S. Infant Botulism Due to Clostridium Botulinum Type C Toxin. Lancet 1990, 336, 1449-1450. [CrossRef]

13. Sonnabend, O.; Sonnabend, W.; Heinzle, R.; Sigrist, T.; Dirnhofer, R.; Krech, U. Isolation of Clostridium Botulinum Type G and Identification of Type G Botulinal Toxin in Humans: Report of Five Sudden Unexpected Deaths. J. Infect. Dis. 1981, 143, 22-27. [CrossRef] [PubMed]

14. Available online: https://emergency.cdc.gov/agent/agentlist-category.asp (accessed on 18 April 2019).

15. Bowman, S.R. Iraqi Chemical and Biological Weapons (CBW) Capabilities. 1998. Available online: https: //www.globalsecurity.org/wmd/library/report/crs/98-129.pdf (accessed on 5 June 2019).

16. United Nations Security Council. Tenth Report of the Executive Chairman of the Special Commission Established by the Secretary-General Pursuant to Paragraph 9(b)(I) of Security Council Resolution 687 (1991) and Paragraph 3 of Resolution 699 (1991) on the Activities of the Special Commission; United Nations Security Council: New York, NY, USA, 1995. 
17. Nowakowski, A.; Wang, C.; Powers, D.B.; Amersdorfer, P.; Smith, T.J.; Montgomery, V.A.; Sheridan, R.; Blake, R.; Smith, L.A.; Marks, J.D. Potent Neutralization of Botulinum Neurotoxin by Recombinant Oligoclonal Antibody. Proc. Natl. Acad. Sci. USA 2002, 99, 11346-11350. [CrossRef] [PubMed]

18. Arnon, S.S.; Schechter, R.; Inglesby, T.V.; Henderson, D.A.; Bartlett, J.G.; Ascher, M.S.; Eitzen, E.; Fine, A.D.; Hauer, J.; Layton, M.; et al. Botulinum Toxin as a Biological Weapon: Medical and Public Health Management. JAMA 2001, 285, 1059-1070. [CrossRef] [PubMed]

19. Black, R.E.; Gunn, R.A. Hypersensitivity Reactions Associated with Botulinal Antitoxin. Am. J. Med. 1980, 69, 567-570. [CrossRef]

20. Arnon, S.S.; Schechter, R.; Maslanka, S.E.; Jewell, N.P.; Hatheway, C.L. Human Botulism Immune Globulin for the Treatment of Infant Botulism. New Engl. J. Med. 2006, 354, 462-471. [CrossRef]

21. Cangene Corp. BAT ${ }^{\circledR}$ [Botulism Antitoxin Heptavalent (A, B, C, D, E, F, G) - (Equine)] Sterile Solution for Injection. Available online: https://www.fda.gov/downloads/../UCM345147.pdf (accessed on 11 October 2017).

22. Amersdorfer, P.; Wong, C.; Chen, S.; Smith, T.; Deshpande, S.; Sheridan, R.; Finnern, R.; Marks, J.D. Molecular Characterization of Murine Humoral Immune Response to Botulinum Neurotoxin Type A Binding Domain as Assessed by Using Phage Antibody Libraries. Infect. Immun. 1997, 65, 3743-3752.

23. Amersdorfer, P.; Wong, C.; Smith, T.; Chen, S.; Deshpande, S.; Sheridan, R.; Marks, J.D. Genetic and Immunological Comparison of Anti-Botulinum Type A Antibodies from Immune and Non-Immune Human Phage Libraries. Vaccine 2002, 20, 1640-1648. [CrossRef]

24. Nayak, S.U.; Griffiss, J.M.; McKenzie, R.; Fuchs, E.J.; Jurao, R.A.; An, A.T.; Ahene, A.; Tomic, M.; Hendrix, C.W.; Zenilman, J.M. Safety and Pharmacokinetics of XOMA 3AB, a Novel Mixture of Three Monoclonal Antibodies Against Botulinum Toxin A. Antimicrob. Agents Chemother. 2014, 58, 5047-5053. [CrossRef]

25. Lou, J.; Geren, I.; Garcia-Rodriguez, C.; Forsyth, C.M.; Wen, W.; Knopp, K.; Brown, J.; Smith, T.; Smith, L.A.; Marks, J.D. Affinity Maturation of Human Botulinum Neurotoxin Antibodies by Light Chain Shuffling Via Yeast Mating. Protein Eng. Des. Sel. PEDS 2010, 23, 311-319. [CrossRef] [PubMed]

26. Pless, D.D.; Torres, E.R.; Reinke, E.K.; Bavari, S. High-Affinity, Protective Antibodies to the Binding Domain of Botulinum Neurotoxin Type A. Infect. Immun. 2001, 69, 570-574. [CrossRef] [PubMed]

27. Meng, Q.; Li, M.; Silberg, M.A.; Conrad, F.; Bettencourt, J.; To, R.; Huang, C.; Ma, J.; Meyer, K.; Shimizu, R.; et al. Domain-Based Assays of Individual Antibody Concentrations in an Oligoclonal Combination Targeting a Single Protein. Anal. Biochem. 2012, 421, 351-361. [CrossRef] [PubMed]

28. Meng, Q.; Garcia-Rodriguez, C.; Manzanarez, G.; Silberg, M.; Conrad, F.; Bettencourt, J.; Pan, X.; Breece, T.; To, R.; Li, M. Engineered Domain-Based Assays to Identify Individual Antibodies in Oligoclonal Combinations Targeting the Same Protein. Anal. Biochem. 2012, 430, 141-150. [CrossRef] [PubMed]

29. Igawa, T.; Tsunoda, H.; Tachibana, T.; Maeda, A.; Mimoto, F.; Moriyama, C.; Nanami, M.; Sekimori, Y.; Nabuchi, Y.; Aso, Y. Reduced Elimination of IgG Antibodies by Engineering the Variable Region. Protein Eng. Des. Sel. 2010, 23, 385-392. [CrossRef]

30. Lacy, D.B.; Stevens, R.C. Sequence Homology and Structural Analysis of the Clostridial Neurotoxins. J. Mol. Biol. 1999, 291, 1091-1104. [CrossRef]

31. Centers for Disease Control and Prevention. Notice of CDC's Discontinuation of Investigational Pentavalent (ABCDE) Botulinum Toxoid Vaccine for Workers at Risk for Occupational Exposure to Botulinum Toxins. MMWR. Morb. Mortal. Wkly. Rep. 2011, 60, 1454-1455.

32. Tomic, M.T.; Espinoza, Y.; Martinez, Z.; Pham, K.; Cobb, R.R.; Snow, D.M.; Earnhart, C.G.; Pals, T.; Syar, E.S.; Niemuth, N. Monoclonal Antibody Combinations Prevent Serotype A and Serotype B Inhalational Botulism in a Guinea Pig Model. Toxins 2019, 11, 208. [CrossRef] [PubMed]

33. Fan, Y.; Dong, J.; Lou, J.; Wen, W.; Conrad, F.; Geren, I.N.; Garcia-Rodriguez, C.; Smith, T.J.; Smith, L.A.; Ho, M.; et al. Monoclonal Antibodies that Inhibit the Proteolytic Activity of Botulinum Neurotoxin Serotype/B. Toxins 2015, 7, 3405-3423. [CrossRef] [PubMed]

34. Garcia-Rodriguez, C.; Razai, A.; Geren, I.N.; Lou, J.; Conrad, F.; Wen, W.H.; Farr-Jones, S.; Smith, T.J.; Brown, J.L.; Skerry, J.C.; et al. A Three Monoclonal Antibody Combination Potently Neutralizes Multiple Botulinum Neurotoxin Serotype E Subtypes. Toxins 2018, 10, 105. [CrossRef]

35. Fan, Y.; Garcia-Rodriguez, C.; Lou, J.; Wen, W.; Conrad, F.; Zhai, W.; Smith, T.J.; Smith, L.A.; Marks, J.D. A Three Monoclonal Antibody Combination Potently Neutralizes Multiple Botulinum Neurotoxin Serotype F Subtypes. PLoS ONE 2017, 12, e0174187. [CrossRef] [PubMed] 
36. Fan, Y.; Barash, J.R.; Lou, J.; Conrad, F.; Marks, J.D.; Arnon, S.S. Immunological Characterization and Neutralizing Ability of Monoclonal Antibodies Directed Against Botulinum Neurotoxin Type H. J. Infect. Dis. 2016, 213, 1606-1614. [CrossRef] [PubMed]

37. Cheng, L.W.; Stanker, L.H.; Lou, J.; Marks, J.D.; Henderson, T.D., 2nd. Antibody Protection Against Botulinum Neurotoxin Intoxication in Mice. Infect. Immun. 2009, 77, 4305-4313. [CrossRef] [PubMed]

38. Leary, S.L.; Underwood, W.; Anthony, R.; Cartner, S.; Corey, D.; Grandin, T.; Greenacre, C.; Gwaltney-Bran, S.; McCrackin, M.; Meyer, R. AVMA Guidelines for the Euthanasia of Animals: 2013 Edition; American Veterinary Medical Association Schaumburg: Schaumburg, IL, USA, 2013.

(C) 2019 by the authors. Licensee MDPI, Basel, Switzerland. This article is an open access article distributed under the terms and conditions of the Creative Commons Attribution (CC BY) license (http://creativecommons.org/licenses/by/4.0/). 